\title{
OBTENÇÃO E UTILIZAÇÃO DA ENZIMA POLIFENOLOXIDASE EXTRAÍdA DE POLPA DE PINHA (Annona squamosa L.) MADURA NO MELHORAMENTO DO SABOR DO CACAU (Theobroma cacao L.) ${ }^{1}$
}

\author{
ELIZA DOROTEA POZZOBON DE ALBUQUERQUE LIMA², GLÁUCIA MARIA PASTORE², SANDRA DRINA FERNANDEZ

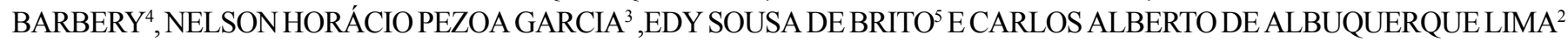

RESUMO - O presente trabalho teve como objetivo estudar a obtenção e a utilização da enzima polifenoloxidase (PPO) extraída de polpa de pinha madura na redução do teor de compostos polifenólicos com a finalidade de diminuir a adstringência e o amargor das amêndoas de cacau processadas na forma de "nibs". A PPO foi extraída com tampão fosfato de potássio 0,025M (pH 7,5), adicionando sulfato de amônio para a precipitação da enzima. O material em pó obtido foi denominado de enzima parcialmente purificada, sendo que a análise de atividade enzimática foi realizada, utilizando-se de catecol como substrato. As características bioquímicas apresentadas foram $\mathrm{pH}$ de estabilidade de 6,0 a 6,5 e temperatura de estabilidade de 10 a $30^{\circ} \mathrm{C}$. Os "nibs" foram autoclavados $\left(121^{\circ} \mathrm{C}\right.$ por 15 minutos $)$ e não autoclavados de amêndoas cruas insuficientemente fermentadas e secas, da mesma origem, sendo embebidas em $25 \mathrm{~mL}$ de uma solução da enzima contendo 200 unidades $/ \mathrm{min} / \mathrm{mL}$, durante 30; 60; 90;210 e 360 minutos, a $23^{\circ} \mathrm{C} \mathrm{e} \mathrm{pH} \mathrm{6,0.} \mathrm{Os} \mathrm{"nibs"} \mathrm{foram} \mathrm{homogeneizados}$ com a solução de enzima a cada 15 minutos, secos, moídos e desengordurados. Após o tratamento enzimático durante 210 minutos realizado nos "nibs" de cacau desengordurado não autoclavados foi possível observar diminuição de $15 \%$ nas concentrações de fenóis totais, $15 \%$ de taninos, $10 \%$ de flavan-3-ois e $18 \%$ de antocianidinas. Os "nibs" de cacau desengordurado autoclavados apresentaram diminuição de $25 \%$ nas concentrações de fenóis totais, $26 \%$ de taninos, $23 \%$ de flavan-3-ois e $51 \%$ de antocianidinas.

Termos para indexação: pinha, polifenoloxidase, polifenóis, cacau.

\section{OBTAINING AND USE OF POLYPHENOLOXIDASE ENZYME EXTRACTED FROM RIPE CUSTARD APPLE (Annona squamosa L.) PULP ON THE COCOA (Theobroma cacao L.) NIBS IN TASTE IMPROVEMENT}

\begin{abstract}
The present work had as aim to study the obtaining and the uses of polyphenoloxidase enzyme (PPO) extracted from ripe custard apple pulp on the reduction of polyphenolic compounds with decrease adstringency and bitterness of cocoa nuts processed at nibs form. The PPO was extracted with $0.025 \mathrm{M}$ potassium phosphate buffer ( $\mathrm{pH} 7.5$ ), adding ammonium sulfate to the enzyme precipitation. The powdered material obtained was called partially purified enzyme, being the analyses of activity carried out with catechol as substract, showing biochemical characteristics of 5.0 to 6.5 stability $\mathrm{pH}$ and 10 to $30^{\circ} \mathrm{C}$ stability temperature the nibs were autoclaved $\left(121^{\circ} \mathrm{C}\right.$ for 15 minutes) and non-autoclaved from the same origin, raw nuts insuficiently fermented and dried were soaked in a solution of the enzyme containing $200 \mathrm{units} / \mathrm{min} / \mathrm{mL}$, for $30,60,90,210$ and 360 minutes, at $23^{\circ} \mathrm{C}$ and $\mathrm{pH} 6.0$. The nibs were homogeneized with the enzyme solution each 15 minutes, dried, ground and became unfatted. After enzymatic treatment over 210 minutes carried out on the non-autoclaved unfatted cocoa nibs, it was possible to observe diminishing of $15 \%$ in the total phenol, $15 \%$ tannin content, $10 \%$ of flavan-3-ois and $18 \%$ of anthocyanidins concentrations. The nibs of autoclaved unfatted cacao showed diminishing of $25 \%$ in the total phenol, $26 \%$ of tannins $23 \%$ of flavan- 3 -ois, and $51 \%$ of anthocyanidins concentrations.
\end{abstract}

Index terms: Custard apple, polyphenoloxidase, polyphenols, cocoa

\section{INTRODUÇÃO}

As enzimas polifenoloxidases (PPO) são amplamente distribuídas na natureza, responsáveis pela oxidação de compostos fenólicos, as quais, na presença de oxigênio, os transformam em quinonas coloridas que participam, posteriormente, das reações de polimerização para dar origem às melonoidinas, caracterizadas pelo aparecimento da coloração marrom-escura.

A presença e a atividade da enzima polifenoloxidase (PPO), durante a fermentação e a secagem das amêndoas de cacau, são um dos fatores responsáveis pelo desenvolvimento dos precursores do sabor, começando na fase oxidativa da fermentação e continuando na secagem (Roelofsen, 1958; VámosVigyázó, 1981; Wong, et al., 1990).

O papel da PPO e a importância da mesma na produção

\footnotetext{
1 (Trabalho 202/2000). Recebido: 11/09/2000. Aceito para publicação: 11/09/2001. Trabalhos desenvolvidos no Curso de Pós-Graduação/FEA/ UNICAMP

2 Professores da UFPB - E-mail:epozzob@zaz.com.br

3 Professores da UNICAMP

4 Mestranda DTA/UNICAMP

5 Doutorando DTA/UNICAMP
} 
do sabor característico de chocolate não estão bem compreendidos; contudo, uma baixa atividade da enzima ou condições que podem levar a uma redução da atividade têm sido apontadas como os fatores responsáveis por uma queda na produção de precursores de sabor de chocolate. A importância desta enzima é freqüentemente mencionada de forma implícita na redução do sabor adstringente do cacau ( Reeves et al., 1988).

Mahanta et al. (1993) estudaram a atividade específica da PPO e peroxidase, responsáveis pela formação de compostos escuros conhecidos como teoflavinas que ocorrem em chá- preto. A maior atividade de ambas as enzimas foi observada na laminação, resultado da injúria mecânica, levando à polimerização oxidativa (escurecimento enzimático) do chá-preto fermentado.

Para Yoshiyama \& Ito (1996), a enzima PPO de fonte microbiana de Coriolus versicolor foi bem efetiva na diminuição da adstringência de sementes de cacau pelos compostos fenólicos como flavonóides e proantocianidinas, bem como diminuindo consideravelmente os compostos fenólicos totais, naturalmente presentes no cacau.

O presente trabalho teve como objetivo estudar a aplicabilidade industrial da enzima polifenoloxidase extraída da polpa de pinha (Annona squamosa L.) madura, como conhecimento fundamental para estabelecer parâmetros de sua utilização na formação de pigmentos e melhoria do sabor de cacau (Theobroma cacao L.).

\section{MATERIAL E MÉTODOS}

A enzima polifenoloxidase (PPO) foi extraída de polpa de pinha madura (Annona squamosa L.) cultivada na região de LinsSP, colhida com \pm 110 dias de desenvolvimento após a floração. O extrato enzimático da polpa de pinha madura foi obtido, utilizando-se $1000 \mathrm{~g}$ de amostra em $2000 \mathrm{~mL}$ de solução tampão fosfato de potássio $0,025 \mathrm{M}(\mathrm{pH} 7,5)$. A extração foi feita a $4^{\circ} \mathrm{C} \mathrm{em}$ liquidificador, durante 3 minutos. O homogeneizado foi centrifugado a $11.000 \mathrm{x}$ g durante 15 minutos a $0^{\circ} \mathrm{C}$, e o sobrenadante mantido a $4^{\circ} \mathrm{C}$, condições desenvolvidas de acordo com Lima \& Pastore (1997). Ao sobrenadante do extrato enzimático bruto, obtido com tampão fosfato de potássio $0,025 \mathrm{M}$ ( $\mathrm{pH} 7,5)$, foi adicionado sulfato de amônio em quantidade suficiente para fornecer $80 \%$ de saturação. O sal foi adicionado lentamente com agitação branda, e a mistura permaneceu em repouso por 24 horas, a $4^{\circ} \mathrm{C}$ para precipitação da enzima. A mistura foi centrifugada a $11.000 \times \mathrm{x}$ por 15 minutos, a $0^{\circ} \mathrm{C}$, reservando-se o precipitado. O precipitado foi dialisado contra água destilada em membrana de acetato de celulose por 24 ou 48 horas, $\mathrm{a} 4^{\circ} \mathrm{C}$. Após a diálise, a fração protéica foi precipitada com álcool etílico gelado a $70 \%$, e sua separação realizada por centrifugação a $11.000 \mathrm{x}$ g durante 15 minutos, a $0^{\circ} \mathrm{C}$, sendo posteriormente seca à temperatura entre 10 e $15^{\circ} \mathrm{C}$ e pulverizada. O material em pó foi denominado de enzima parcialmente purificada obtida por Lima \& Pastore (1997) e Lima (1999).

A atividade da PPO foi determinada através da mistura de reação constituída de $0,1 \mathrm{~mL}$ da solução de enzima parcialmente purificada, 1,2 $\mathrm{mL}$ de substrato catecol $15 \mathrm{mM}$ em tampão fosfato de potássio $0,025 \mathrm{M}(\mathrm{pH} 7,0)$ e $1,7 \mathrm{~mL}$ do mesmo tampão fosfato de potássio $0,025 \mathrm{M}(\mathrm{pH} 7,0)$, perfazendo um total de 3,0 mL. Para o branco, foi usada a mistura de solução tampão mais solução do substrato. A atividade da enzima foi calculada pela inclinação linear da curva. Uma unidade de atividade de PPO foi definida como a quantidade da enzima que ocasiona um aumento na absorbância de 0,001/min/mL (Oktay et al.,1995).

Foi estudada a redução de substâncias polifenólicas, utilizando a polifenoloxidase parcialmente purificada em pó, extraída de polpa de pinha madura (Annona squamosa L.) com atividade inicial de $7.000 \mathrm{U} / \mathrm{min} / \mathrm{mL}$, para o preparo da solução de enzima com $200 \mathrm{U} / \mathrm{min} / \mathrm{mL}$, apresentando $\mathrm{pH}$ e temperatura de estabilidade de 6,0 a 7,5 e de 10 a $30{ }^{\circ} \mathrm{C}$, respectivamente (Lima \& Pastore, 1997; Lima, 1999). O efeito do $\mathrm{pH}$ na estabilidade da atividade da PPO foi estudado na faixa de $\mathrm{pH} \mathrm{3,0}$ a 10,0. A solução enzimática foi misturada com tampão de diferentes $\mathrm{pH}$ incubada na temperatura ótima $\left(20^{\circ} \mathrm{C}\right)$ por 20 horas, de acordo com Fujita et al. (1988) e Fujita et al. (1991). Foram utilizados os sistemas tampões citrato-fosfato $0,1 \mathrm{M}(\mathrm{pH} 3,0$ a 5,5), fosfato de potássio $0,05 \mathrm{M}(\mathrm{pH} 6,0$ a 8,0) e Tris- $\mathrm{HCl} 0,1 \mathrm{M}(\mathrm{pH} 8,5$ a 10,0). A atividade enzimática residual de PPO foi determinada de acordo como descrito anteriormente. Para o estudo da estabilidade térmica da PPO parcialmente purificada, tratou-se uma solução de enzima $1 \%$, colocando-se alíquotas em tubos de ensaio com tampas e pré-incubando a temperaturas de $10 ; 15 ; 20 ; 30 ; 40 ; 50$; $60 ; 70$ e $80^{\circ} \mathrm{C}$ por 30 minutos, de acordo com Fujita et al. (1988). Após o tempo de tratamento, as soluções foram resfriadas imediatamente e a atividade enzimática residual determinada. $\mathrm{O}$ tratamento com polifenoloxidase foi realizado em "nibs" autoclavados (121 ${ }^{\circ} \mathrm{C}$ durante 15 minutos) e em "nibs" não autoclavados. Para cada tratamento enzimático, $50 \mathrm{~g}$ de "nibs", para cada replicata, foram de amêndoas cruas insuficientemente fermentadas e secas, da mesma origem, sendo embebidas em $25 \mathrm{~mL}$ de uma solução da enzima contendo $200 \mathrm{U} / \mathrm{min} / \mathrm{mL}$, durante 30; 60; 90; 210 e 360 minutos, a $23^{\circ} \mathrm{C} \mathrm{e} \mathrm{pH} \mathrm{6,0.} \mathrm{Os} \mathrm{"nibs"} \mathrm{foram}$ homogeneizados com a solução de enzima a cada 15 minutos, secos, moídos e desengordurados.

A extração dos fenóis foi realizada segundo a metodologia modificada, descrita por Bartolomé et al. (1995), dos "nibs" finamente moídos e desengordurados com hexano. Do pó desengordurado e seco, foram pesadas alíquotas de $1 \mathrm{~g}$ para extração com $15 \mathrm{~mL}$ de uma solução de acetona/água (70:30) em refrigeração a $4^{\circ} \mathrm{C}$, com agitação durante 20 minutos, e finalmente centrifugadas por 10 minutos, a $2.942 \mathrm{x}$ g. Alíquotas de $0,5 \mathrm{~mL}$ do sobrenadante foram completadas com $0,5 \mathrm{~mL}$ de água destilada e submetidas à determinação. A quantificação de fenóis totais foi realizada de acordo com metodologia descrita por Price \& Butler(1977).

Para a extração de taninos, alíquotas de $0,05 \mathrm{~g}$ de pó de cacau desengordurado foram pesadas e extraídas em 4 etapas

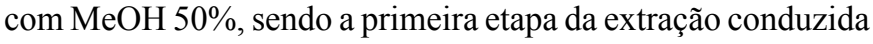
com $2 \mathrm{~mL}$ de $\mathrm{MeOH} 50 \%$ com agitação durante 8 minutos; a segunda etapa foi realizada em um banho de água a $80-85^{\circ} \mathrm{C}$ com $2 \mathrm{~mL}$ de $\mathrm{MeOH}$ 50\% sem agitação, com tempo de permanência de 8 minutos; a terceira etapa foi idêntica à segunda; e a quarta etapa foi realizada com adição de $4 \mathrm{~mL}$ de $\mathrm{MeOH} 50 \%$ nas mesma condições das anteriores. Ao final do processo de extração, foram obtidos $10 \mathrm{~mL}$ de extrato. A quantificação foi realizada seguindo a metodologia descrita por Hargerman \& Butler (1978).

A determinação de flavan-3-ois foi conduzida seguindo a metodologia modificada, descrita por Maillard et al. (1996). 
Para a quantificação, alíquotas de pó de cacau desengordurado e seco de $0,025 \mathrm{~g}$ foram extraídas 4 vezes, durante 10 minutos, com $10 \mathrm{~mL}$ de $\mathrm{MeOH}$ em cada extração. Todos os extratos reunidos foram filtrados através de papel de filtro evaporado para secagem. O resíduo foi dissolvido em $5 \mathrm{~mL}$ de sulfato de amônia $(400 \mathrm{~g} / \mathrm{L})$. Esta mistura foi acidificada até $\mathrm{pH} 3,0$ com ácido metafosfórico $(200 \mathrm{~g} / \mathrm{mL})$ e, com a ajuda de um funil de separação, realizaram-se 3 extrações com $10 \mathrm{~mL}$ de acetato de etila em cada extração. Os $30 \mathrm{~mL}$ recuperados da extração foram evaporados, obtendo-se um resíduo seco que, posteriormente, foi dissolvido em $15 \mathrm{~mL}$ de MeOH. Para a quantificação, utilizou-se de uma curva padrão com diferentes concentrações de $(+)$ catequina $(0,2 ; 0,3 ; 0,4 ; 0,5 ; 0,6 ; 0,7$ e $0,8 \mathrm{mg} / \mathrm{mL})$.

A determinação de antocianidinas foi realizada seguindo a metodologia modificada, descrita por Oszmianski \& Sapis (1988), em Wilska-Jeska \& Koren (1996). Para a extração e quantificação, foi utilizado $0,05 \mathrm{~g}$ de pó de cacau desengordurado e seco, sendo extraídos 4 vezes com 2,5 mL de uma solução de $\mathrm{HCl}$ 1,5 N e etanol absoluto (85:15) com agitação durante 3 minutos em cada extração e finalmente centrifugação durante 5 minutos a $3.397 \mathrm{xg}$. O total dos sobrenadantes $(10 \mathrm{~mL})$ foram recolhidos num béquer e evaporados até a secura, sendo que o resíduo foi dissolvido em $5 \mathrm{~mL}$ de etanol e a leitura realizada em espectrofotômetro a 535 e $460 \mathrm{~nm}$, com resultados expressos em unidades de absorbância.

\section{RESULTADOS E DISCUSSÃO}

Os resultados das características bioquímicas da enzima PPO, parcialmente purificada de polpa de pinha madura em relação ao $\mathrm{pH}$ e temperatura de estabilidade aplicada neste estudo, são mostrados nas Figuras 1 e 2. A Figura 1 indica que a enzima foi estável entre pH 6,0 a 7,5 e reteve ao redor de $90 \%$ de atividade na faixa de $\mathrm{pH} 6,0$ a 8,0 .

A Figura 2 ilustra que a PPO foi estável nas temperaturas de 10 a $30^{\circ} \mathrm{C}$ durante 1 hora, sendo inativada rapidamente em temperaturas superiores a $50^{\circ} \mathrm{C}$. Estes resultados garantiram a aplicação da enzima no processo de melhoria dos "nibs" do cacau.

A Tabela 1 apresenta os resultados da quantificação de fenóis totais em pó de cacau desengordurado obtido a partir de "nibs" de cacau tanto autoclavados como não autoclavados

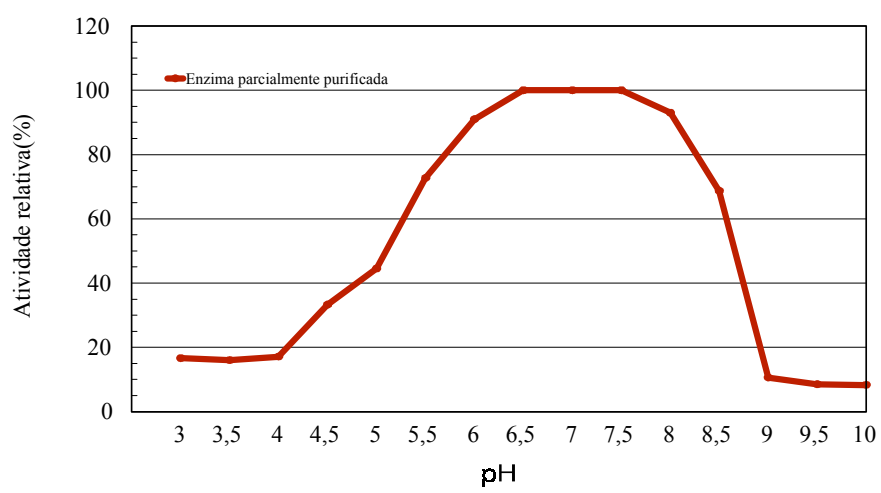

FIGURA 1 - Efeito do $\mathrm{pH}$ na estabilidade da enzima polifenoloxidase parcialmente purificada em polpa de pinha madura. com e sem tratamento enzimático. A diminuição de fenóis totais no tratamento enzimático dos "nibs" não autoclavados chegou a 15\% após 210 minutos; já no caso dos "nibs" autoclavados, esta perda chegou a $24 \%$. Estas percentagens foram obtidas em relação a "nibs" não autoclavados e sem tratamento enzimático. Estes resultados são consistentes com os relatos de Yoshiyama \& Ito (1996), no sentido de que a diminuição de fenóis totais com o uso de PPO, em "nibs" de cacau insuficientemente fermentados, atingiu valores na ordem de $25 \%$.

A Tabela 2 apresenta os resultados da quantificação de taninos em pó desengordurado obtido a partir de "nibs" autoclavados e não autoclavados tratados enzimaticamente. Pode-se observar que a diminuição de taninos, após 210 minutos de tratamento, chegou a $15 \%$ no caso dos "nibs" não autoclavados e a $26 \%$ nos "nibs" autoclavados.

Observa-se, na Tabela 3, que apresenta os resultados da quantificação de flavan-3-ois em pó desengordurado obtido a partir de "nibs" autoclavados e não autoclavados tratados enzimaticamente, que a perda de flavan-3-ois, após 210 minutos de tratamento, chegou a $10 \%$ no caso dos "nibs" não autoclavados e a $23 \%$ nos "nibs" autoclavados. A autoclavagem aqui, como em todos os outros tratamentos, teve uma influência positiva no que diz respeito à ação da enzima, aumentando consideravelmente a diminuição dos compostos polifenólicos.

Os resultados apresentados na Tabela 3 diferem dos resultados relatados por Yoshiyama \& Ito (1996), que obtiveram uma redução na ordem de $55 \%$. Essa diferença, com nossos resultados, pode ser atribuída às condições de processo e mesmo à origem da PPO utilizada.

$\mathrm{Na}$ Tabela 4, pode-se observar os resultados da quantificação de antocianidinas realizada em pó desengordurado que fora obtido a partir de "nibs" autoclavados e não autoclavados tratados enzimaticamente. Novamente a diminuição dos compostos polifenólicos em "nibs" autoclavados foi maior comparada com a diminuição em "nibs" não autoclavados; contudo, a diminuição dos compostos fenólicos foi significativa nos dois tratamentos.

A diminuição de antocianidinas, após 210 minutos de tratamento, chegou, no caso dos "nibs" não autoclavados, a $18 \%$ e a $51 \%$ nos "nibs" autoclavados. Como aconteceu com os resultados encontrados para a redução de fenóis totais, os

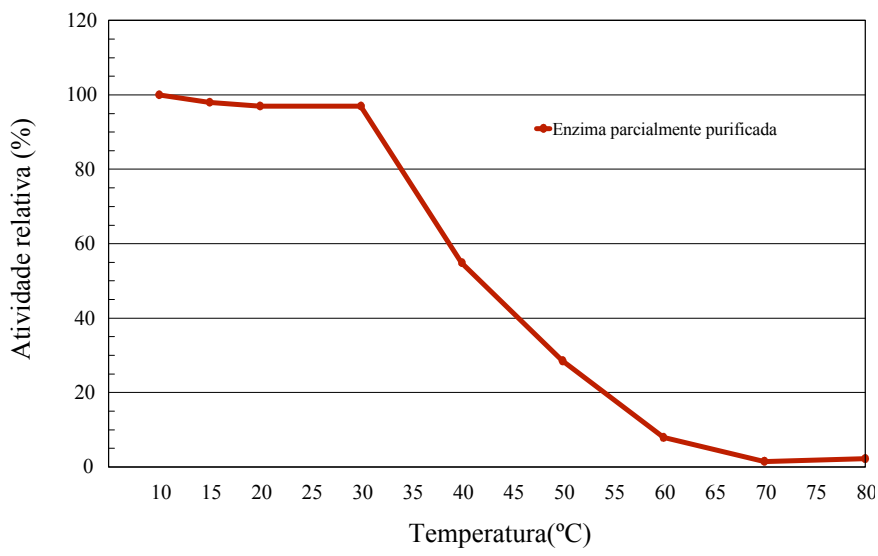

FIGURA 2 - Efeito da temperatura na estabilidade da enzima polifenoloxidase parcialmente purificada em polpa de pinha madura. 
TABELA 1 - Concentração de fenóis totais em pó de cacau desengordurado, tratado com a enzima polifenoloxidase.

\begin{tabular}{|c|c|c|}
\hline 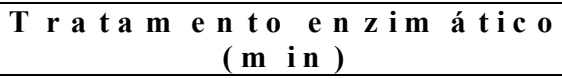 & $\begin{array}{c}\text { N ã o a u to c la va d o } \\
(\%)\end{array}$ & $\begin{array}{c}\text { A u to c la v a d o } \\
(\%)\end{array}$ \\
\hline 30 & $25,75 \mathrm{a} \pm 0,4$ & $24,94 a \pm 0,4$ \\
\hline 90 & $23,21_{\mathrm{c}} \pm 0,5$ & 23,66 ab $\pm 0,3$ \\
\hline 150 & $22,58 \mathrm{c} \pm 0,3$ & $21,07 \mathrm{bc} \pm 0,4$ \\
\hline 210 & $22,34 \mathrm{c} \pm 0,3$ & $19,87_{\mathrm{c}} \pm 0,4$ \\
\hline
\end{tabular}

Os valores de uma mesma coluna, com a mesma letra, não diferem significativamente entre si (Teste de Tukey, a $5 \%$ de significância).

TABELA 2 - Concentração de taninos em pó de cacau desengordurado, tratado com a enzima polifenoloxidase.

\begin{tabular}{|c|c|c|}
\hline $\begin{array}{c}\text { Tratam ento e nzim ático } \\
(m \text { in })\end{array}$ & $\begin{array}{c}\text { Nã o a toclavad o } \\
(\%)\end{array}$ & $\begin{array}{c}\text { A u toc lavad o } \\
(\%)\end{array}$ \\
\hline Sem enzim a & $7,81 \pm 0,2$ & $7,26 \pm 0,1$ \\
\hline 30 & $7,85 \mathrm{a} \pm 0,2$ & $7,08 \mathrm{a} \pm 0,2$ \\
\hline 60 & $7,83 a \pm 0,1$ & $6,47 \mathrm{ab} \pm 0,2$ \\
\hline 90 & $7,47 \mathrm{ab} \pm 0,2$ & $6,23 \mathrm{bc} \pm 0,1$ \\
\hline 150 & $6,64 \mathrm{bc} \pm 0,2$ & $6,08 \mathrm{bcd} \pm 0,1$ \\
\hline 210 & $6,59 \mathrm{bc} \pm 0,1$ & $5,71_{\mathrm{cd}} \pm 0,2$ \\
\hline 360 & $6,23_{c} \pm 0,2$ & $5,39{ }_{\mathrm{d}} \pm 0,1$ \\
\hline
\end{tabular}

Os valores de uma mesma coluna, com a mesma letra, não diferem significativamente entre si (Teste de Tukey, a 5\% de significância).

TABELA 3 - Concentração de flavan-3-ois em pó de cacau desengordurado, tratado com a enzima polifenoloxidase.

\begin{tabular}{|c|c|c|}
\hline 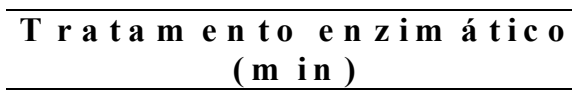 & $\begin{array}{c}N \text { ã o a u to cla la a d o } \\
(\%)\end{array}$ & $\begin{array}{c}\text { A u toc la v a d o } \\
(\%)\end{array}$ \\
\hline Sem e n zim a & $23,16 \pm 0,3$ & $23,28 \pm 0,4$ \\
\hline 30 & $23,10_{\mathrm{a}} \pm 0,3$ & $19,71_{\mathrm{a}} \pm 0,3$ \\
\hline 150 & $22,47 \mathrm{a} \pm 0,3$ & $20,59_{\mathrm{a}} \pm 0,3$ \\
\hline 210 & $20,80_{\mathrm{a}} \pm 0,4$ & $17,75 \mathrm{a} \pm 0,4$ \\
\hline 360 & $18,39 \mathrm{a} \pm 0,2$ & $16,02_{\mathrm{a}} \pm 0,2$ \\
\hline
\end{tabular}

Os valores de uma mesma coluna, com a mesma letra, não diferem significativamente entre si (Teste de Tukey, a 5\% de significância).

TABELA 4 - Quantificação de antocianidinas em pó de cacau desengordurado, tratado com a enzima polifenoloxidase.

\begin{tabular}{|c|c|c|}
\hline $\begin{array}{c}\text { Tratam ento enzim ático } \\
(m \text { in })\end{array}$ & $\begin{array}{c}\text { N ã o a u toclavad o } \\
(\%)\end{array}$ & $\begin{array}{c}\text { A u toclavad } 0^{1} \\
(\%)\end{array}$ \\
\hline Sem enzim a & $2,12 \pm 0,1$ & $1,83 \pm 0,1$ \\
\hline 30 & $1,88_{\mathrm{a}} \pm 0,1$ & $1,61_{\mathrm{a}} \pm 0,2$ \\
\hline 60 & $1,87_{\mathrm{a}} \pm 0,1$ & $1,48_{\mathrm{ab}} \pm 0,1$ \\
\hline 90 & $1,73_{\mathrm{b}} \pm 0,2$ & $1,40_{a b} \pm 0,1$ \\
\hline 150 & $1,72 \mathrm{~b} \pm 0,1$ & $1,21_{b c} \pm 0,2$ \\
\hline 210 & $1,73_{b} \pm 0,2$ & $1,02_{\mathrm{c}} \pm 0,1$ \\
\hline 360 & $1,63_{\mathrm{c}} \pm 0,2$ & $1,03_{\mathrm{c}} \pm 0,1$ \\
\hline
\end{tabular}

(Valores obtidos na leitura de absorbâncias $(535 \mathrm{~nm} / 462), 1 \mathrm{~A} / 1 \mathrm{~B}$.

Os valores de uma mesma coluna, com a mesma letra, não diferem significativamente entre si (Teste de Tukey, a 5\% de significância).

resultados na diminuição de antocianidinas são próximos dos dados relatados por Yoshiyama \& Ito (1996). Estes pesquisadores determinaram que, após o tratamento enzimático com PPO, o teor de redução das antocianidinas, em pó de cacau pouco fermentado, ficou em torno de $55 \%$, e que foi o mais alto comparado com os outros polifenóis. Após observar a redução destes compostos (antocianidinas), durante o tratamento enzimático, e baseado no relato de Hancock (1988), que relaciona a redução de antocianidinas e taninos com uma diminuição da adstringência no cacau, é possível sugerir que esta diminuição tem uma relação direta com uma queda na adstringência característica de amêndoas pouco fermentadas (violetas). Esta diminuição foi levantada por alguns provadores durante a análise sensorial realizada com o produto tratado enzimaticamente.

\section{CONCLUSÕES}

A partir dos resultados deste estudo, pode-se concluir que o tratamento enzimático com a polifenoloxidase extraída da polpa de pinha madura possibilitou melhorar o sabor dos "nibs" de cacau, pois: 
1. Apresentou redução significativa dos compostos fenólicos, presentes no cacau insuficientemente fermentado, através do uso da enzima polifenoloxidase.

2. Obteve-se uma redução significativa dos teores de antocianidinas em "nibs" autoclavados e tratados enzimaticamente, onde, conseqüentemente, a cor violeta característica da pigmentação destas antocianidinas diminui, dando lugar à cor marrom característica de um cacau fermentado.

\section{REFERÊNCIAS BIBLIOGRÁFICAS}

BARTOLOMÉ,B.; JIMÉNEZ-RAMSEY, L.M.; BUTLER, L.G.Nature of the condensed tannins present in the dietary fibre fractions in foods. Food Chemistry, Kidlington, v.53, n.4, p.357362,1995 .

FORSYTH,W.G.C.,QUESNEL,V.C.Cacao glycosidase and colour changes during fermentation. Journal Science Food Agriculture, v.8, p.505-509, 1957.

FORSYTH,W.G..C.Cacao polyphenolic substances.2.Changes during fermentation. Biochemistry Journal, v.51,p.516-529, 1952.

GREGORY,R.P.F.,BENDALL, D.S.The purification and some properties of the polyphenoloxidase from tea (Camelia sinensis L.). Biochemistry, Washington, v101,p.569-572,1966

HAGERMAN,A.E.,BUTLHER,L.G.Protein precipitation method for the quantitative determination of tannins. Journal of Agricultural and Food Chemistry, Washington, v.26,n.4,p.809813,1978 .

HANCOCK,B.L.Fabricación y utilización industrial del chocolate. Producción y transporte del haba de cacao. Zaragoza:Editorial Acribia,1988.p.9-32.

FUJITA, S.; TONO, T. Purification and some properties of polyphenoloxidase in eggplant (Solanum melongena). Journal Science Food Agriculture, v. 46, p. 115-123, 1988.

FUJITA, S.; TONO, T.; KAWAHARA, H. Purification of polyphenol oxidase in head lettuce (Lactuca sativa). Journal of Food Science, Chicago, v.55, p. 643- 651, 1991.

LIMA,E.D.P.A., PASTORE,G.M. Purificação parcial e caracterização bioquímica da enzima polifenoloxidase (PPO) em fruto da família Anonácea - pinha (Annona squamosa L.). In: SIMPÓSIO LATINO-AMERICANO DE CIÊNCIA DE ALIMENTOS, 2., 1997, Campinas. Anais... p.89.

LIMA,E.D.P.A. Purificação e caracterização bioquímica da polifenoloxidase (PPO) em fruto da família anonácea - pinha (Annona squamosa L.). 1999. 132 f. Tese (Doutorado em Ciência de Alimentos)-Faculdade de Engenharia de Alimentos, Universidade Estadual de Campinas.

MAHANTA, P. K.,BORUAH,S.K.,BORUAH,H.K.,KALITA,J.N. Changes of polyphenol oxidase and peroxidase activities and pigment composition of some manufactured black tea (Camellia sinensis L.). American Chemical Society, v.41,p.272-276,1993.

MAILLARD,M.N.,SOUM,M.H.,BOIVIN,P.,BERSET,C.Antioxidant activity of barley and malt: relationship with phenolic content. Lebensm. Wiss, u. Technology, Sindri, v.29,p.238-244,1996.

OKTAY, M., KÜFREVIOGLU, I., KOCACALISKANI. SAKIROGLU, H. Polyphenoloxidase from Amasya apple. Journal of Food Science, Chicago, v.60, n.3, p.494-505,1995.

OSZMIANSKI,J.,SAPIS,J.C.Anthocyanins in fruits of Aronia melanocarpa (chokeberry). Journal of Food Science, Chicago, v.53, n. 4,1988 .

PRICE,M.L.,BUTLER,L.G.Rapid visual estimation and spectrophometric determination of tannin content of sorghum grain. Journal of Agricultural and Food Chemistry, Washington, v.25,n.6,p.1268-1273,1977.

QUESNEL,V.C.Agents inducing the death of cacao seed during fermentation. Journal Science Food Agriculture, v.16,p.441447,1965 .

REEVES, S.G., MCDOWELL,I., BEHN,K., DENCH,J. Biochemical studies of Cocoa Bean o-diphenol $\mathrm{O}_{2}$ oxidoreductase (catechol oxidase). Food Chemistry, Kidlington, 290-219,1988.

ROELOFSEN,P.A.Fermentation dryng and storage of cocoa beans. Advances in Food Research, San Diego, p.226-229, 1958.

YOSHIYAMA, M.; ITO, Y.Decrease of adstringency of cacao beans by an enzymatic treatment. Nippon Shokuhin Kagaku Kogaku Kaishi, Minato, v.43, n.2, p.124-129,1996.

WILSKA-JESZKA.,KORZUCHOWSKA,A.Anthocyanins and chlorogenic acid copigmentation- Influence on the colour of strawberry and chokeberry juices. Zlebensm Unters Forsch, v.203,p.38-42,1996.

WONG,M.K.,DIMICK,P.S.,HAMMERSTEDT, R.H. Extraction and high performance liquid chromatographic enrichment of polyphenol oxidase from Theobroma cacao seeds. Journal of Food Science, Chicago, v.55,n.4,p.1108-1111,1990.

VÁMOS-VIGYÁZÓ, L.Polyphenoloxidase and peroxidase in fruit and vegetables.CRC-Critical Reviews in Food Science and Nutrition, n.49,1981. 